\title{
Prevalence and characteristics of venous thromboembolism in severe exacerbation of chronic obstructive pulmonary disease in a tertiary care hospital in India
}

\author{
Soibam Pahel Meitei ${ }^{1}$, Sudheer Tale ${ }^{1}$, Arjun Kumar Negi ${ }^{1}$, Ruchi Dua ${ }^{1}$, Rohit Walia ${ }^{2}$, Sudhir Saxena ${ }^{3}$ \\ ${ }^{1}$ Department of Pulmonary Medicine; ${ }^{2}$ Department of Cardiology; ${ }^{3}$ Department of Radiodiagnosis, All India Institute \\ of Medical Sciences, Rishikes, India
}

\begin{abstract}
Acute exacerbation of chronic obstructive pulmonary disease (AECOPD) carries a high risk of venous thromboembolism
\end{abstract}

Correspondence: Soibam Pahel Meitei, Department of Pulmonary Medicine, All India Institute of Medical Sciences, Rishikes 249203, India.

Tel.+91 8729877476. E-mail address: dr.pmsoibam@gmail.com.

Authors' contribution: SPM, ST, AKN, RD, RW, SS, concept, SPM, ST, AKN, RD, RW, SS, design, SPM, ST, AKN, RD, RW, SS, definition of intellectual content, SPM, literature research, SPM, clinical studies, SPM, experimental studies, SPM, ST, AKN, data acquisition, SPM, ST, AKN, data analysis, SPM, statistical analysis, SPM, manuscript preparation, SPM, RD, RW, SS, manuscript editing, SPM, ST, $\mathrm{RD}, \mathrm{RW}, \mathrm{SS}$, manuscript review, SPM, ST, guarantor.

Funding: The present study was funded by The Research Cell, AIIMS, Rishikesh, India.

Informed consent: Written informed consent was obtained from legally authorized representatives for anonymized patient information to be published in this article.

Ethical approval: The study protocol was approved by the Institutional Ethics Committee of All India Institute of Medical Sciences,

Rishikesh (vide letter no: AIIMS/IEC/19/654).

Conflict of interest: The authors declare no potential conflict of interests.

Acknowledgments: The authors would like to thank Dr. Girish Sindhwani, professor and head of the Department of Pulmonary Medicine, AIIMS, Rishikesh, and Dr. Rishi Gupta, biostatistician for AIIMS, Delhi, India.

Key words: Compression ultrasound; chronic obstructive pulmonary disease; CT pulmonary angiography; pulmonary embolism; venous thromboembolism.

Received for publication: 21 December 2020.

Accepted for publication: 7 March 2021.

${ }^{\circ}$ Copyright: the Author(s), 2021

Licensee PAGEPress, Italy

Monaldi Archives for Chest Disease 2021; $91: 1742$

doi: 10.4081/monaldi.2021.1742

This article is distributed under the terms of the Creative Commons Attribution Noncommercial License (by-nc 4.0) which permits any noncommercial use, distribution, and reproduction in any medium, provided the original author(s) and source are credited.
(VTE). Pulmonary embolism (PE) and AECOPD increase the mortality and morbidity risk associated with each other. Racial and ethnic differences in VTE risk have been documented in multiple studies. However, there is a dearth of reliable Indian data on the same. This study was planned to find the prevalence of VTE in the setting of severe AECOPD in a tertiary care hospital in India and to identify the clinical, laboratory and radiological characteristics of VTE in severe AECOPD. A total of 156 consecutive patients admitted with severe AECOPD and meeting the specified inclusion and exclusion criteria were recruited. Thorough workup of all patients was done including arterial blood gas (ABG), serum D dimer, electrocardiogram (ECG), compression ultrasound of lower limbs and 2-D echocardiography. Patients with high pre-test probability score, or intermediate pre-test probability score at presentation with serum D dimer above the age adjusted cut-off underwent computerised tomography pulmonary angiography (CTPA). Results were analysed using SPSS version 23. Sixteen (10.3\%) patients had VTE, 15 $(93.75 \%)$ of them being cases of isolated PE. Female gender, higher cumulative past exposure to corticosteroid, higher alveolar-arterial gradient, right ventricular dysfunction, and higher mean pulmonary artery pressure were associated with increased risk for VTE. The prevalence of VTE in AECOPD in this study among an Indian population is higher than among other Asians, but lower than among the Blacks, the Caucasians and the Middle-East ethnicities. Since a vast majority of VTE presents as PE without deep vein thrombosis (DVT) in the setting of AECOPD, the absence of deep vein thrombosis of lower limbs does not rule PE in the setting.

\section{Introduction}

Pulmonary embolism (PE) may precipitate acute exacerbation of chronic obstructive pulmonary disease (AECOPD) or can develop during the course of in- hospital stay for the same. Previous studies have found a varying yet high prevalence of PE in AECOPD, ranging from $18-25 \%[1,2]$. Another study found an increased risk of unsuspected and fatal $\mathrm{PE}$ among patients with chronic obstructive pulmonary disease (COPD) [3].

COPD nearly doubles the risk of PE and other venous thromboembolic (VTE) events [4], the presumed pathophysiology being an interaction between chronic systemic inflammatory process in COPD with the coagulation pathway leading to a prothrombotic state [5]. The risk is amplified during AECOPD because of the heightened airway and systemic inflammation [6]. Presence of COPD doubles the risk of mortality in patients 
with PE [7]. While the delay in the diagnosis and treatment of PE translates into increased mortality and poor outcomes [8], early detection of PE in the setting of AECOPD remains a challenge because of similar symptoms and signs [9]. Many studies have documented racial and ethnic differences in terms of the risk for VTE, and found the rate of VTE to be in the following order: American Blacks $>$ Caucasians $>$ Hispanics $>$ South Asians $>$ Asians [10,11]. Till the time of planning for this study, only one study had been conducted so far in India that had found a VTE prevalence of $9 \%$ among patients with AECOPD $(n=100)$. [12] However, the study had used only deep vein thrombosis (DVT), diagnosed by venous doppler study of lower limbs, as a surrogate marker of PE. CT pulmonary angiography (CTPA) was not used to diagnose pulmonary embolism. Our study was intended to find the prevalence of VTE in severe AECOPD in a tertiary care centre in North India by using compression ultrasound and CTPA to diagnose VTE and to identify the clinical, laboratory and radiological characteristics of VTE in severe AECOPD.

\section{Materials and Methods}

This single centre prospective observational study was done in Pulmonary Medicine Ward and Respiratory Intensive Care Unit of AII India Institute of Medical Sciences, Rishikesh, India from March 2019 to February 2020. We recruited a total of 156 consecutive patients of severe AECOPD who met the inclusion criteria (admission with severe AECOPD, informed consent and age $\geq 18$ years) and the exclusion criteria (admission because of reasons other than disease severity, absence of informed consent, pregnancy, malignancy, patient unfit to undergo CTPA because of impaired renal function or iodine allergy, ongoing anticoagulant treatment for previous VTE or any other indication or known hypercoagulable states like Protein C, S or AT deficiency or Factor V Leiden mutation). The sample size was calculated based on $9 \%$ prevalence of VTE in the lone similar study done previously [12]. Severe AECOPD was defined, as per the GOLD Report 2019 [13], as an event in the natural course of the disease characterized by a change in the patient's baseline dyspnea, cough, and/or sputum production that is beyond the normal day-to-day variations, acute in onset, and with sufficient severity warranting admission in the hospital. Work up was done in line with Evaluation of patients with suspected acute pulmonary embolism: best practice advice from the Clinical Guidelines Committee of the American College of Physicians 2015 [14]. Prevention protocol for VTE was as per 2012 ACCP Guideline on prevention of VTE in nonsurgical patients [15] and treatment protocol was as per 2016 ACCP Guideline on antithrombotic therapy for venous thromboembolic disease [16]. Detailed medical history taking and physical examination were done. Modified Wells and Revised Geneva scores were calculated at presentation.

Apart from routine investigations, serum $\mathrm{D}$-dimer and $\mathrm{C}$ reactive protein levels, arterial blood gas (ABG), electrocardiogram (ECG) and Chest X-ray were done for all patients. Compression ultrasound (CUS) of both lower limbs was done for all patients on presentation, and as clinically indicated. The proximal deep venous system between the proximal common femoral vein (CFV) and the trifurcation of the popliteal vein (PV) in the calf was checked for compressibility at $1 \mathrm{~cm}$ intervals. Non-compressibility of the veins was considered indicative of thrombosis (DVT).

2-D echocardiography was done at presentation for all patients and as indicated later on. Right ventricular dysfunction with left- ward bulging of the interventricular septum or/and D shaped left ventricle, hypokinesis of the right ventricular free wall (with sparing of the apical portion: McConnell sign) and direct visualization of thrombus in the right ventricle were noted. Right ventricular systolic pressure (RVSP) was derived from the tricuspid regurgitation jet velocity in the apical 4 chamber view. Mean pulmonary artery pressure (mPAP) was derived from the formula: $\mathrm{mPAP}=0.61 \times \mathrm{RVSP}+2$.

CT pulmonary angiography (CTPA) was done as soon as feasible for a) patients with high risk Modified Wells Score or Revised Geneva Score and b) patients with intermediate risk categories by Wells Score or Geneva Score plus D dimer value higher than the age adjusted cut off value of $[10 \times$ Age (in years) $\mathrm{mcg} / \mathrm{L}$. CTPA was done with Siemens Somatom Definition Plus 128 Slice Duel Energy during breath- holding with injection of non-ionic contrast material [Iodixanol; VISIPAQUE TM-320(GE Healthcare Shanghai Co. Ltd, Shanghai, China)] at the dose of $1.5 \mathrm{ml} / \mathrm{kg}$ body weight infused with a power injector at the rate of $5 \mathrm{ml} / \mathrm{s}$ and using a slice thickness of $5 \mathrm{~mm}$, with automated tube voltage and current. The reconstruction interval was $1 \mathrm{~mm}$. Consultant radiologists read the images. PE was diagnosed if there was an intraluminal defect, or if the vessel was occluded by low-attenuation material.

Primary outcomes were the prevalence and types of VTE in AE-COPD. Secondary outcomes were clinical, laboratory and radiological predictors of VTE.

Statistical analysis was done using SPSS Statistical Software Version 23. Data description was done in terms of mean (standard deviation), median (interquartile range), or frequencies and percentages, as appropriate. A comparison of numerical variables between the study groups were done using Wilcoxon signed rank test: odds ratios of association of these numerical variables with VTE and with mortality was derived by univariate logistic regression analysis. For comparing categorical data, Chi square test was used: Fischer's Exact Test was used when the expected frequency was less than 5 . P values less than 0.05 were considered statistically significant. Multivariate logistic regression analysis was done to find the strength of association of various parameters with venous thromboembolism and mortality.

\section{Results}

\section{Patient characteristics}

A total of 156 patients were recruited, with a mean (SD) age of 63.44 (9.54) years. Of them, $35(22.6 \%)$ were female. Other patient characteristics are summarized in Table 1.

\section{Primary outcomes}

A total of 16 patients were diagnosed with VTE, giving an overall prevalence of $10.3 \%$. Eight patients were confirmed by CTPA. Another eight were clinically diagnosed cases of pulmonary embolism, based on overall clinical picture (rapid onset shortness of breath with hypoxemia and hypotension) together with 2-D Echo evidence of new onset right ventricular dysfunction, D-dimer positivity above the age adjusted cut-off value, exclusion of other causes and subsequent decision of the treating team to make a clinical diagnosis of pulmonary embolism even though the patients could not undergo CTPA since they were unfit for transport for the same (Table 2). 


\section{Secondary outcomes}

\section{Background clinical characteristics as predictors of VTE}

The following were found to be significantly associated $(p<0.05)$ with VTE: female gender, smoking index, COPD duration, COPD GOLD group, cumulative oral steroid previously taken and cumulative inhaled corticosteroid previously taken (Table 3).

\section{Clinical characteristics at presentation as predictors of VTE}

Significant association was noted between venous thromboembolism and symptoms of rapid onset shortness of breath (with peak intensity occurring within 6 hours of onset), non-specific chest pain and lower limb swelling, and Modified Wells Score at presentation (Table 4).

\section{Laboratory and radiological characteristics as predictors of VTE}

There was a significant association of VTE with pulse rate; ECG findings of right axis deviation and right bundle branch block; Xray chest findings of pleural effusion, prominent pulmonary artery and consolidation; 2D echocardiography findings of right ventricular dysfunction, McConnell sign and high mean pulmonary artery pressure; neutrophil-lymphocyte (NL) Ratio in peripheral blood, $\mathrm{D}$ dimer and $\mathrm{C}$ reactive protein (CRP): and alveolar arterial (A-a) Gradient at presentation (Table 5).

Table 1. Demographic and background clinical information $(n=156)$.

\begin{tabular}{|c|c|}
\hline Parameters & $\begin{array}{c}\text { Frequency }(\%) \\
\text { or mean } \pm \text { SD }\end{array}$ \\
\hline $\begin{array}{l}\text { Age } \\
\text { 30-39 Years } \\
\text { 40-49 Years } \\
\text { 50-59 Years } \\
\text { 60-69 Years } \\
\text { 70-79 Years } \\
\text { 80-89 Years } \\
\geq 90 \text { Years }\end{array}$ & $\begin{array}{c}1(0.6) \\
12(7.7) \\
32(20.5) \\
67(42.9) \\
37(23.7) \\
6(3.8) \\
1(0.6)\end{array}$ \\
\hline $\begin{array}{l}\text { Gender } \\
\text { Male } \\
\text { Female }\end{array}$ & $\begin{array}{l}121(77.6) \\
35(22.4)\end{array}$ \\
\hline $\begin{array}{l}\text { COPD Gold group } \\
\text { A } \\
\text { B } \\
\text { C } \\
\text { D }\end{array}$ & $\begin{array}{l}22(14.1) \\
28(17.9) \\
33(21.2) \\
73(46.8)\end{array}$ \\
\hline $\begin{array}{l}\text { Co-morbidity } \\
\text { Hypertension } \\
\text { Diabetes } \\
\text { Coronary artery disease } \\
\text { Obesity } \\
\text { Obstructive sleep apnea } \\
\text { Right heart failure }\end{array}$ & $\begin{array}{c}23(14.7) \\
27(17.3) \\
14(9.0) \\
3(1.9) \\
5(3.2) \\
35(22.4)\end{array}$ \\
\hline $\begin{array}{l}\text { Smoking index* } \\
\text { COPD duration (years) }\end{array}$ & $\begin{array}{c}814.62 \pm 357.00 \\
5.72 \pm 2.73\end{array}$ \\
\hline $\begin{array}{l}\text { Cumulative dose of steroid taken (prior to admi } \\
\text { Oral corticosteroid dose (prednisolone, mg) } \\
\text { Inhaled corticosteroid dose (budesonide, mg) }\end{array}$ & $\begin{array}{c}818.03 \pm 525.27 \\
1200.32 \pm 635.72\end{array}$ \\
\hline
\end{tabular}

\section{Predictors of mortality of VTE in severe COPD}

Post hoc analysis suggested an association of mortality among patients with VTE (PE) with female gender, mean pulmonary artery pressure, CRP $(\mathrm{mg} / \mathrm{L})$, interval between onset of increased shortness of breath to presentation, duration of invasive ventilation required and duration of hospital stay (Table 6).

\section{Discussion}

The prevalence of VTE was found to be $10.3 \%$ among the patients with severe AECOPD. While it compares well with the prevalence of $9 \%$ found in the Indian study done in 2011 by Dutta et al. [12], the latter did not use CTPA to diagnose PE. The systematic review by Aleva et al. in 2017 [2] found a $16.1 \%$ prevalence of PE among patients with AECOPD. However, the individual studies included in the review had diverse populations of different races and ethnicities. The higher prevalence was driven by higher prevalence in non-Asian populations. Multiple Asian ethnicities have been documented to have lower incidence of VTE as compared to other races [11]. Hence, prevalence of VTE in Indians seems to be lower than in the Blacks, the Caucasians and Middle-East ethnicities but higher than in other Asians.

In our study, $15(93.75 \%)$ cases had PE as the sole manifestation of VTE. Only one patient had concomitant DVT of lower limb and PE. None of the patients had DVT as the sole manifestation of VTE. While this finding contrasts that of the

earlier Indian study by Dutta et al., [12] it is in agreement with multiple international studies that have found that VTE in COPD and asthma patients manifests more frequently as PE than as DVT $[2,17,18]$. Non-usage of CTPA in the study by Dutta et al. might have led to many cases of PE having been missed. From the pathophysiological point of view, this may point towards the possibility of in situ thrombosis of the pulmonary artery or its branches. From the clinical point of view, absence of deep vein thrombosis does not rule out pulmonary embolism.

The meta-analysis by Aleva et al. found no relation between age or gender and the risk of VTE among patients with AECOPD

Table 2. Prevalence and types of VTE in severe AECOPD ( $n=156)$.

\begin{tabular}{lc} 
Parameters & $\begin{array}{c}\text { Frequency (\%) } \\
\text { or mean } \pm \text { SD }\end{array}$ \\
Venous thromboembolism (VTE) $(\mathrm{n}=156)$ & \\
Prevalence & $16(10.3)$ \\
VTE type $(\mathrm{n}=16)$ & \\
DVT+PE B/L PA & $1(6.2)$ \\
PE: Sub-massive (clinical) & $1(6.2)$ \\
PE: Massive (clinical) & $7(43.8)$ \\
PE: MPA+LPA & $1(6.2)$ \\
PE: MPA+RPA & $1(6.2)$ \\
PE: RPA & $2(12.5)$ \\
PE: Segmental-U/L & $2(12.4)$ \\
PE-Subsegmental-B/L & $1(6.2)$ \\
Total & $16(100)$ \\
Presentation-VTE diagnosis interval (hours) $(\mathrm{n}=16)$ & \\
Mean $\pm S D$ & $112.50 \pm 63.63$ \\
Median $\pm I Q R$ & $96 \pm 48$ \\
\hline
\end{tabular}

B/L, bilateral; DVT, deep vein thrombosis; LPA, left pulmonary artery; MPA, main pulmonary artery; PA, pulmonary artery; RPA, right pulmonary artery; U/L, unilateral. 
[2]. In our study, we also found no statistically significant association between age and risk for VTE. However, among the general population age has been shown to be associated with the risk of VTE in some other studies [19,20].

In our study, VTE prevalence figures for females and males were $20.00 \%$ and $7.44 \%$ respectively $\left(\mathrm{X}^{\wedge 2}=4.654, \mathrm{p}=0.052\right)$,
Odds ratios being 3.08 (95\% CI 1.06- 9) for female and 0.32 (95\% CI 0.11-0.95) for male. While the association between gender and VTE among the general population has been conflicting [21,22], our finding echoes that of a study done specifically among patients with COPD, that found significantly higher prevalence of VTE among women [23]. Whether this gender dif-

Table 3. VTE and background demographic and clinical parameters $(n=156)$.

\begin{tabular}{|c|c|c|c|}
\hline Parameters & & is thromboemb & \\
\hline & $\begin{array}{l}\text { Present } \\
(n=16)\end{array}$ & $\begin{array}{l}\text { Absent } \\
(n=140)\end{array}$ & p \\
\hline Age (years) & $64.69 \pm 8.84$ & $63.30 \pm 9.64$ & $0.563^{1}$ \\
\hline $\begin{array}{l}\text { Gender } \\
\text { Male } \\
\text { Female }\end{array}$ & $\begin{array}{l}9(56.2 \%) \\
7(43.8 \%)\end{array}$ & $\begin{array}{l}112(80.0 \%) \\
28(20.0 \%)\end{array}$ & $0.052^{2}$ \\
\hline $\begin{array}{l}\text { Co-morbidity } \\
\text { Hypertension } \\
\text { Diabetes } \\
\text { Coronary artery disease } \\
\text { Obesity } \\
\text { Obstructive sleep apnea } \\
\text { Right heart failure }\end{array}$ & $\begin{array}{c}0(0.0 \%) \\
4(25.0 \%) \\
0(0.0 \%) \\
0(0.0 \%) \\
0(0.0 \%) \\
3(18.8 \%)\end{array}$ & $\begin{array}{c}23(16.4 \%) \\
23(16.4 \%) \\
14(10.0 \%) \\
3(2.1 \%) \\
5(3.6 \%) \\
32(22.9 \%)\end{array}$ & $\begin{array}{l}0.131^{2} \\
0.482^{2} \\
0.364^{2} \\
1.000^{2} \\
1.000^{2} \\
1.000^{2}\end{array}$ \\
\hline Smoking index* & 568.75291 .48 & $\pm 842.71 \pm 353.83$ & $0.002^{3}$ \\
\hline COPD duration (years)* & $6.88 \pm 1.75$ & $5.59 \pm 2.80$ & $0.040^{3}$ \\
\hline $\begin{array}{l}\text { COPD Gold group* } \\
\text { A } \\
\text { B } \\
\text { C } \\
\text { D }\end{array}$ & $\begin{array}{c}1(6.2 \%) \\
0(0.0 \%) \\
1(6.2 \%) \\
14(87.5 \%)\end{array}$ & $\begin{array}{l}21(15.0 \%) \\
28(20.0 \%) \\
32(22.9 \%) \\
59(42.1 \%)\end{array}$ & $0.006^{2}$ \\
\hline Oral corticosteroid dose (prednisolone, $\mathrm{mg}$ ) ${ }^{* * *}$ & $1532.81 \pm 837.06$ & $735.15 \pm 406.00$ & $<0.001^{3}$ \\
\hline Inhaled corticosteroid dose (budesonide, $\mathrm{mg}$ ) ${ }^{* * *}$ & $1693.38 \pm 715.88$ & $1143.97 \pm 603.47$ & $0.001^{3}$ \\
\hline
\end{tabular}

Table 4. VTE and clinical parameters at presentation.

\begin{tabular}{|c|c|c|c|}
\hline Parameters & $\begin{array}{l}\text { Present } \\
(n=16)\end{array}$ & $\begin{array}{l}\text { Absent } \\
(n=140)\end{array}$ & p \\
\hline $\begin{array}{l}\text { Symptoms } \\
\text { Rapid onset shortness of breath* } \\
\text { Non-specific chest pain* } \\
\text { Anginal chest pain } \\
\text { Pleuritic chest pain } \\
\text { Haemoptysis } \\
\text { Syncope } \\
\text { Lower limb swelling* }\end{array}$ & $\begin{array}{c}9(56.2 \%) \\
13(81.2 \%) \\
0(0.0 \%) \\
0(0.0 \%) \\
2(12.5 \%) \\
2(12.5 \%) \\
13(81.2 \%)\end{array}$ & $\begin{array}{c}34(24.3 \%) \\
21(15.0 \%) \\
1(0.7 \%) \\
10(7.1 \%) \\
2(1.4 \%) \\
4(2.9 \%) \\
64(45.7 \%)\end{array}$ & $\begin{array}{l}0.015^{2} \\
<0.00^{1} \\
1.000^{2} \\
0.600^{2} \\
0.053^{2} \\
0.116^{2} \\
0.007^{4}\end{array}$ \\
\hline $\begin{array}{l}\text { Clinical probability score at presentation } \\
\text { Modified Wells score category* } \\
\text { Low risk } \\
\text { Intermediate risk } \\
\text { Revised Geneva score category } \\
\text { Low risk } \\
\text { Intermediate risk }\end{array}$ & $\begin{array}{c}13(81.2 \%) \\
3(18.8 \%) \\
0(0.0 \%) \\
16(100.0 \%)\end{array}$ & $\begin{array}{c}136(97.1 \%) \\
4(2.9 \%) \\
1(0.7 \%) \\
139(99.3 \%)\end{array}$ & $1.000^{2}$ \\
\hline Body mass index $\left(\mathrm{kg} / \mathrm{m}^{2}\right)$ & $24.12 \pm 2.80$ & $23.34 \pm 1.78$ & $0.055^{3}$ \\
\hline Pulse rate (bpm)* & $126.56 \pm 24.92$ & $116.09 \pm 12.95$ & $0.009^{3}$ \\
\hline Mean arterial pressure (mmHg) & $87.50 \pm 11.32$ & $87.04 \pm 12.54$ & $0.879^{1}$ \\
\hline Pulsus paradoxus & $1(6.2 \%)$ & $7(5.0 \%)$ & $0.588^{2}$ \\
\hline Asymmetric lower limb swelling or pain & $1(6.2 \%)$ & $0(0.0 \%)$ & $0.103^{2}$ \\
\hline
\end{tabular}

***Significant at $\mathrm{p}<0.05 ;{ }^{1}$-test; ${ }^{2}$ Fisher's exact test; ${ }^{3}$ Wilcoxon test; ${ }^{4}$ Chi-squared test; rapid onset shortness of breath: Acute onset shortness of breath with peak intensity occurring within six hours of onset. 
ference has to do with the more severe disease (higher degree of inflammatory reaction) in response to smoking [24] or biomass fuel exposure, or with the gender disparity in healthcare access [25] (delayed access of female patients of COPD to healthcare leading to prolonged exposure to pro-thrombotic inflammatory disease pathology) in the Indian sub-continent needs further exploration.
There was a significant difference in terms of smoking index (W=592.000, $\mathrm{p}=0.002$ ), with the median (IQR) smoking index being 600 (225) (range: 0 - 1200) among patients with venous thromboembolism and 800 (400) (range: 0 - 1800) among patients without venous thromboembolism. While it is in agreement with the meta-analysis by Aleva et al. [2], it contrasts other meta-analyses $[26,27]$ of studies done among the general popula-

Table 5. Association of VTE with laboratory and radiological characteristics.

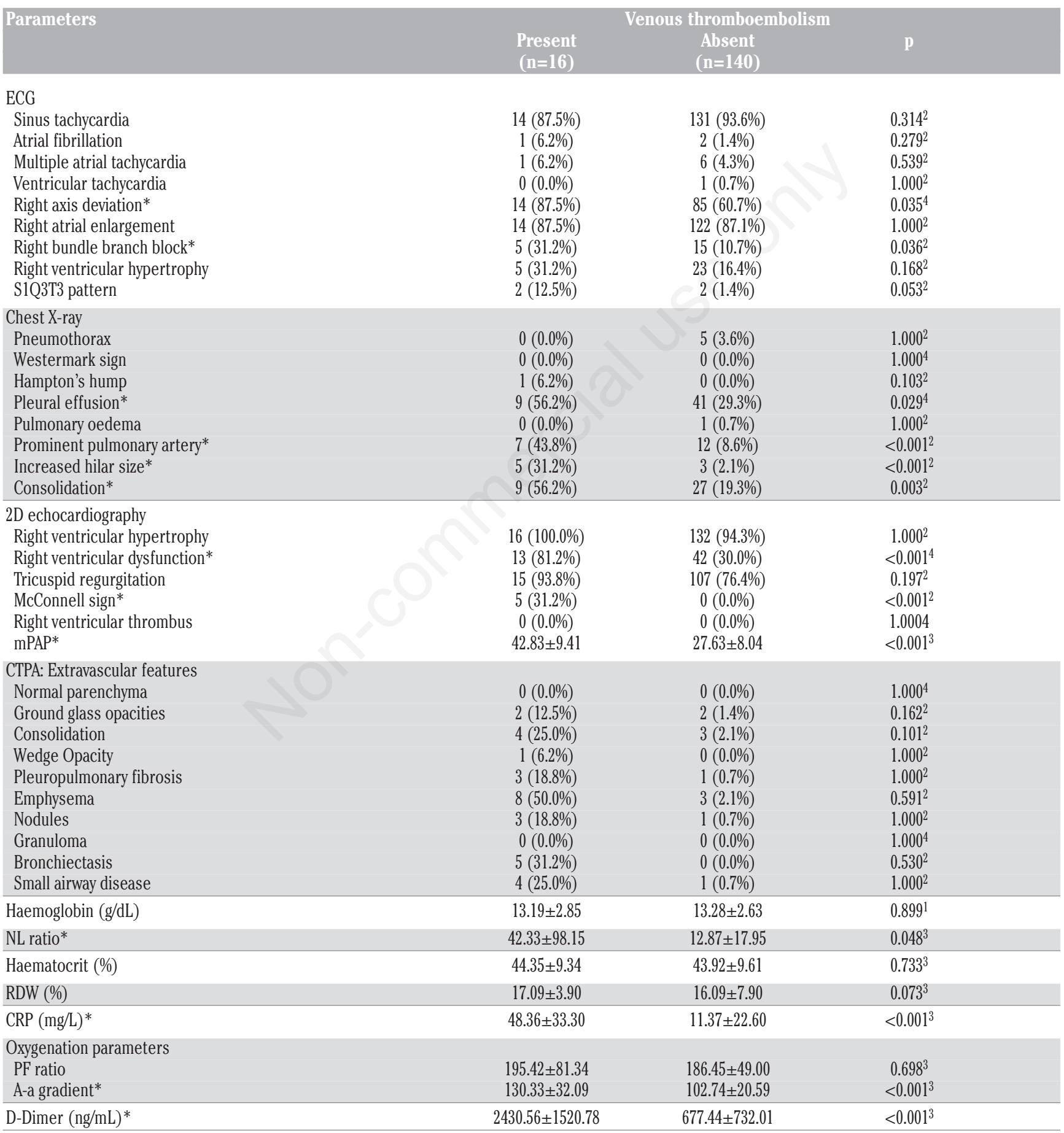

***Significant at $\mathrm{p}<0.05 ;{ }^{1} \mathrm{t}$-test; ${ }^{2}$ Fisher's exact test; ${ }^{3}$ Wilcoxon test; ${ }^{4}$ Chi-squared test; CTPA, CT pulmonary angiography; RDW, red cell distribution width; $\mathrm{NL}_{\text {ratio: }}$ neutrophil lymphocyte ratio; $\mathrm{PF}$ ratio: PaO $\mathrm{O}_{2}$ /FiO ${ }_{2}$; A-a gradient: alveolar arterial gradient of $\mathrm{PO}_{2}$. 
tion. Hence, this finding is in contrast to findings of most other studies, perhaps because of reporting bias among our study population. A few studies done among the general population found a significant positive correlation between BMI and the risk for VTE [20,28] while Samuel et al. [29] found no such relation. Among the patients with AECOPD, Aleva et al. found no correlation of BMI with risk for PE in AECOPD [2], a finding that is similar to ours. Hence, a higher BMI may not portend a higher risk for VTE among patients with AECOPD.

There was no significant association of hypertension, diabetes, coronary artery disease or obstructive sleep apnea with the risk for VTE in our study population. This finding is in line with those of the meta-analysis of patients with AECOPD by Aleva et al. [2] and another meta-analysis that included studies done in the general population [27]. Another recent study by Gregson et al. concluded that there was an inconsistent association of VTE with diabetes and blood pressure [20] in the general population. However, a few studies had supported the hypothesis that obstructive sleep apnea may be an independent risk factor for VTE in the general population [30,31]. Our study failed to show any such association in the population of patients with AECOPD.

There was a significant difference in the median duration of COPD (W=1466.50, $\mathrm{p}=0.04)$, with the median duration of COPD being 8 years (interquartile range 3 years) in the patient group with VTE and 5 years (interquartile range 4.25) in the group without VTE. While an earlier study that explored the relation of COPD duration with the risk for venous thromboembolism did not find any relation between the two [32], the positive correlation that we found in our study may be explained by the fact that disease duration has a direct correlation with the increasing incidence and severity of two disease-related complications known to have an association with venous thromboembolism: pulmonary hypertension and right sided heart failure.

Dong et al. found that the risk of VTE in COPD patients increased with the degree of airway obstruction [33]. However, binary logistic regression in our study did not yield any significant association between the COPD GOLD Group and the risk for venous thromboembolism.
Increased risk of VTE has been associated with both endogenous and exogenous glucocorticoid excess [34,35]. Current use of oral corticosteroids was associated with increased risk of recurrent PE (OR 3.74; 95\% CI 2.04-6.87) [36]. A similar trend was observed for inhaled corticosteroids, although it did not reach statistical significance $(\mathrm{p}=0.10)$. Our study also found that an increase in cumulative dose of oral corticosteroid by $837.1 \mathrm{mg}$ (one SD) above the mean of $1532.8 \mathrm{mg}$ increased the risk of VTE by an OR of 3.44 (95\% CI 1.96-6.04, p <0.001). Similarly, an increase in cumulative dose of inhaled corticosteroid by 715.9 $\mathrm{mg}$ (one SD) above the mean of $1693.4 \mathrm{mg}$ increased the risk of VTE by an OR of 2.14 (95\% CI 1.32-3.50, p <0.001). Hence, reduction of exposure of COPD patients to steroid either in the oral form or the inhaled form may be a strategy to reduce the risk of VTE.

The metanalysis by Aleva et al. [2] found that pleuritic chest pain and signs of cardiac failure were more frequent among patients of AECOPD with VTE than those without. Our study found multiple clinical markers showing significant association with VTE among patients with AECOPD: rapid onset shortness of breath (defined for the purpose of the current study as acute onset increased shortness of breath with peak intensity occurring within 6 hours of onset) with OR of 4.01 (95\% CI 1.39-11.58), non-specific chest pain with OR of $24.56(95 \% \mathrm{CI}$ 6.44-93.62) and lower limb swelling with OR of $5.15(95 \% \mathrm{CI}$ 1.4-18.86).

There was a significant association of high A-a gradient, an increase in 32.1 (one SD) above the mean of 130.3 increasing the risk of VTE by an OR of 2.70 (95\% CI 1.59-4.61, p<0.001). A recent prospective study also concluded that $\mathrm{A}-\mathrm{a} \mathrm{O} 2$ gradient values were clinically important in the diagnosis of patients with $\mathrm{PE}$ although it might be incapable of detection of severity of PE [37].

Presence of consolidation on Xray (that correlated with clinical diagnosis of pneumonia) increased the risk of VTE by an $\mathrm{OR}=5.38(95 \% \mathrm{CI} 1.84-15.74, \mathrm{p}=0.007)$. This finding is in agreement with that of another study [38].

Presence of right axis deviation increased the risk of VTE by an OR of $10.11(95 \%$ CI 2.74-37.34), $\mathrm{p}=<0.001)]$. In the same way, presence of right bundle branch block (RBBB) gave an OR

Table 6. Mortality among VTE patients, and clinical, laboratory and radiological characteristics.

\begin{tabular}{|c|c|c|c|}
\hline Parameters & $\begin{array}{l}\text { Survived } \\
(\mathrm{n}=8)\end{array}$ & $\begin{array}{l}\text { Outcomes } \\
\text { Expired } \\
(n=8)\end{array}$ & p \\
\hline $\begin{array}{l}\text { Gender* } \\
\text { Male } \\
\text { Female }\end{array}$ & $\begin{array}{l}6 \\
2\end{array}$ & $\begin{array}{c}3 \text { (33.33\% among males) } \\
5 \text { (71.43\% among females) }\end{array}$ & $0.046^{1}$ \\
\hline Duration of hospital stay (days)* & $15.25 \pm 9.18$ & $7.12 \pm 4.32$ & $0.031^{1}$ \\
\hline Shortness of breath onset to presentation interval (hours)* & $359.25 \pm 359.06$ & $80.25 \pm 47.02$ & $0.037^{1}$ \\
\hline Mean arterial pressure (mmHg) & $92.92 \pm 8.32$ & $82.08 \pm 11.75$ & $0.058^{1}$ \\
\hline 2D echocardiography: mPAP* & $37.84 \pm 9.54$ & $47.83 \pm 6.47$ & $0.020^{1}$ \\
\hline $\mathrm{CRP}(\mathrm{mg} / \mathrm{L}) *$ & $33.65 \pm 39.00$ & $63.06 \pm 19.00$ & $0.028^{1}$ \\
\hline $\begin{array}{l}\text { Oxygenation at presentation } \\
\text { PF ratio } \\
\text { A-a gradient }\end{array}$ & $\begin{array}{l}183.12 \pm 67.41 \\
130.55 \pm 23.56\end{array}$ & $\begin{array}{l}207.72 \pm 96.38 \\
130.11 \pm 40.63\end{array}$ & $\begin{array}{l}0.574^{1} \\
0.574^{1}\end{array}$ \\
\hline D-Dimer (ng/mL) & $2613.88 \pm 1914.96$ & $2247.25 \pm 1100.93$ & $0.958^{1}$ \\
\hline Duration of hospital stay (days)* & $15.25 \pm 9.18$ & $7.12 \pm 4.32$ & $0.031^{1}$ \\
\hline
\end{tabular}


of $3.79(95 \%$ CI 1.16-12.39), $\mathrm{p}=0.036)$. Presence of S1Q3T3 pattern gave an OR of 9.86 (95\% CI 1.29-75.47, $\mathrm{p}=0.053)$. The above findings agree with those of earlier studies $[39,40]$.

Right ventricular dysfunction (RVD) in the setting of an AECOPD can be because of AECOPD per se, right ventricular infarct, acute pulmonary embolism or arrhythmias [41]. Adaptive changes in the RV myocardium occur in chronic pulmonary hypertension that help maintain RV stroke volume. However, this does not occur in the acute setting of acute pulmonary embolism, and the RV in normal people is unable to acutely generate a mean pressure $>40 \mathrm{mmHg}$ [41]. Interaction of long-standing pulmonary hypertension in COPD patients with the pressure changes in acute pulmonary embolism is complex. However, our study found that presence of RVD conferred an OR of 10.11 (95\% CI 2.74-37.34, $\mathrm{p}=<0.001)$ for the diagnosis of VTE. An increase in mean pulmonary arterial pressure (mPAP) by 9.4 $\mathrm{mmHg}$ (one SD) above the mean of $42.8 \mathrm{mmHg}$ was associated with an OR of $4.76(95 \%$ CI 2.52-9.01, $<<0.001)$ for the diagnosis of VTE.

Since 2014, when Guany et al. [42] proposed neutrophil-lymphocyte ratio (NLR) on peripheral blood count as an inflammatory marker in COPD patients, several studies have shown that NLR is associated with airflow limitation, disease severity, exacerbation frequency, hospitalization, and all-cause mortality $[43,44]$. However, the association between NLR and VTE only showed a trend towards significance, with an increase by 98.15 (one SD) above the value of 42.33 being associated with an OR of $1.60(0.93-2.77, \mathrm{p}=0.090)$.

In a previous study, CRP was found to have a moderate association with PE in emergency department patients [45]. As a marker of inflammation, serum CRP is higher in COPD patients than in normal subjects, and its levels in stable COPD patients were found to correlate with FEV1 and 6-minute walk distance [46]. In the setting of AECOPD, CRP levels are increased further [47]. Our study found that a rise in serum CRP by $33.3 \mathrm{mg} / \mathrm{L}$ (one SD) above the mean of $48.4 \mathrm{mg} / \mathrm{L}$ was associated with an increased risk of VTE by an OR of 2.40 (1.50$3.82, \mathrm{p}<0.001)$.

Because of the small sample size that was not powered to study the predictors of mortality, regression analysis did not yield any statistically significant results. However, there was a trend towards significance for the association of in-hospital mortality with female gender, mean pulmonary artery pressure and CRP level. Larger studies can be planned to explore these associations. Of particular note, mortalities among VTE cases were $71.43 \%$ (OR 5.0) for females and $33.33 \%$ for males.

\section{Limitations of the study}

The study was only powered for finding out the prevalence of VTE among patients of severe exacerbation of COPD. Autopsy was not performed for confirming the diagnosis of patients with AECOPD with fatal outcome since the patients' family members did not consent for the same. Follow up of the VTE cases after discharge could not be done because of noncooperation from and loss to follow up of majority of them. Hence, data on mortality and morbidity outcome after discharge from the hospital could not be obtained. However, the strength of the study lies in the fact that it was a real-world study done in a tertiary care hospital.

\section{Conclusions}

Overall prevalence of VTE was $10.3 \%$ among patients admitted with severe AECOPD in the tertiary care setting in India. Prevalence of VTE among Indians thus seems to be lower than among the Blacks, the Caucasians and the Middle-East ethnicities but higher than among other Asians. VTE in acute exacerbation of COPD presents predominantly as isolated PE. Female gender was associated with higher risk (OR 3.06) of VTE in patients with severe AECOPD, and with higher risk for death if they develop PE (OR 5.00). Higher cumulative doses of prior exposure to oral and inhaled corticosteroid were associated with a higher risk for VTE. Rapid onset shortness of breath, non-specific chest pain and lower limb swelling should alert the clinician to look for the presence of PE in patients with severe AECOPD. High A-a gradient at presentation in the Emergency Department may be a marker of PE. RVD and high mPAP in patients with severe AECOPD may be echocardiographic markers for VTE. High levels serum CRP, when detected in patients with severe AECOPD, may be a marker of VTE.

\section{Clinical implications and future directions}

In the setting of AECOPD, absence of clinical signs of DVT should not be used to lower the index of suspicion of PE. Factors associated with higher risk for PE in the setting of AECOPD include female gender, high dose of previous steroid exposure, rapid onset shortness of breath with peak in 6 hours, high A-a gradient, high CRP, high mPAP and RVD on 2-D Echocardiography. A clinical risk score is in the process of being formulated by incorporating the above risk factors for further validation in bigger well-planned studies.

\section{References}

1. Shapira-Rootman M, Beckerman M, Soimu U, et al. The prevalence of pulmonary embolism among patients suffering from acute exacerbations of chronic obstructive pulmonary disease. Emerg Radiol 2015;22:257-60.

2. Aleva FE, Voets LWLM, Simons SO, et al. Prevalence and localization of pulmonary embolism in unexplained acute exacerbations of COPD: a systematic review and meta-analysis. Chest 2017;151:544-54.

3. Pineda LA, Hathwar VS, Grant BJ. Clinical suspicion of fatal pulmonary embolism. Chest 2001;120:791-5.

4. Sidney S, Sorel M, Quesenberry CP, et al. COPD and incident cardiovascular disease hospitalizations and mortality: Kaiser Permanente Medical Care Program. Chest 2005;128:2068-75.

5. Saghazadeh A, Rezaei N. Inflammation as a cause of venous thromboembolism. Crit Rev Oncol Hematol 2016;99:272-85.

6. Hurst JR, Perera WR, Wilkinson TMA, et al. Systemic and upper and lower airway inflammation at exacerbation of chronic obstructive pulmonary disease. Am J Respir Crit Care Med 2006;173:71-8.

7. Goldhaber SZ, Visani L, De Rosa M. Acute pulmonary embolism: clinical outcomes in the International Cooperative Pulmonary Embolism Registry (ICOPER). Lancet Lond Engl 1999;353:1386-9. 
8. Lesser B. The diagnosis of acute pulmonary embolism in patients with chronic obstructive pulmonary disease. Chest;1992:17-22.

9. Tillie-Leblond I, Marquette C-H, Perez T, et al. Pulmonary embolism in patients with unexplained exacerbation of chronic obstructive pulmonary disease: prevalence and risk factors. Ann Intern Med 2006;144:390-6.

10. White RH, Keenan CR. Effects of race and ethnicity on the incidence of venous thromboembolism. Thromb Res 2009;123 Suppl 4:S11-17.

11. Tran H. The risk of venous thromboembolism is lower in multiple asian ethnic groups. Circulation;2018 Mar:AMP 18.

12. Dutt TS, Udwadia ZF. Prevalence of venous thromboembolism in acute exacerbations of chronic obstructive pulmonary disease: an Indian perspective. Indian J Chest Dis Allied Sci 2011;53:207-10.

13. Global Initiative for Obstructive Lung Disease. 2019.http://goldcopd.org/ (accessed 8 Jan 2019).

14. Raja AS, Greenberg JO, Qaseem A, et al. Evaluation of patients with suspected acute pulmonary embolism: best practice advice from the Clinical Guidelines Committee of the American College of Physicians. Ann Intern Med 2015;163:701.

15. Kahn SR, Lim W, Dunn AS, et al. Prevention of VTE in nonsurgical patients. Chest 2012;141:e195S-e226S.

16. Kearon C, Akl EA, Ornelas J, et al. Antithrombotic therapy for VTE disease: CHEST Guideline and expert panel report. Chest 2016;149:315-52.

17. Bertoletti L, Quenet S, Laporte S, et al. Pulmonary embolism and 3-month outcomes in 4036 patients with venous thromboembolism and chronic obstructive pulmonary disease: data from the RIETE registry. Respir Res 2013;14:75.

18. Majoor CJ, Kamphuisen PW, Zwinderman AH, et al. Risk of deep vein thrombosis and pulmonary embolism in asthma. Eur Respir J 2013;42:655-61.

19. Bizien N, Noel-Savina E, Tromeur C, et al. Age is a major risk factor of venous thromboembolism (VTE). Eur Respir J 2011;38.https://erj.ersjournals.com/content/38/Suppl_55/p393 6 (accessed 3 May 2020).

20. Gregson J, Kaptoge S, Bolton T, et al. Cardiovascular risk factors associated with venous thromboembolism. JAMA Cardiol 2019;4:163.

21. Martinez C, Cohen AT, Bamber L, et al. Epidemiology of first and recurrent venous thromboembolism: a population-based cohort study in patients without active cancer. Thromb Haemost 2014;112:255-63.

22. Roach REJ, Cannegieter SC, Lijfering WM. Differential risks in men and women for first and recurrent venous thrombosis: the role of genes and environment. J Thromb Haemost 2014; 12:1593-600.

23. Kwon YS, Choi W-I, Lee CW, et al. Sex difference of venous thromboembolism risk in chronic obstructive pulmonary disease and interstitial lung disease. Clin Exp Thromb Hemost 2017;3:24-30.

24. Sørheim I-C, Johannessen A, Gulsvik A, et al. Gender differences in COPD: are women more susceptible to smoking effects than men? Thorax 2010;65:480-5.

25. Maharana B, Ladusingh L. Gender disparity in health and food expenditure in India among elderly. Int J Popul Res 2014;2014:150105.

26. Cheng Y-J, Liu Z-H, Yao F-J, et al. Current and former smoking and risk for venous thromboembolism: a systematic review and meta-analysis. PLoS Med 2013;10:e1001515.
27. Mahmoodi BK, Cushman M, Anne Næss I, et al. Association of traditional cardiovascular risk factors with venous thromboembolism: an individual participant data meta-analysis of prospective studies. Circulation 2017;135:7-16.

28. Glynn RJ, Rosner B. Comparison of risk factors for the competing risks of coronary heart disease, stroke, and venous thromboembolism. Am J Epidemiol 2005;162:975-82.

29. Samuel S, Gomez L, Savarraj JP, et al. Assessment of the relationship between body mass index and incidence of venous thromboembolism in hospitalized overweight and obese patients. Pharmacotherapy 2017;37:893-9.

30. Deflandre E, Degey S, Opsomer N, et al. Obstructive sleep apnea and Smoking as a risk factor for venous thromboembolism events: review of the literature on the common pathophysiological mechanisms. Obes Surg 2016;26:640-8.

31. Lippi G, Mattiuzzi C, Franchini M. Sleep apnea and venous thromboembolism. A systematic review. Thromb Haemost 2015;114:958-63.

32. Erelel M, Çuhadaro Ğ Ç, Ece T, et al. The frequency of deep venous thrombosis and pulmonary embolus in acute exacerbation of chronic obstructive pulmonary disease. Respir Med 2002;96:515-8.

33. Dong W, Zhu Y, Du Y, et al. Association between features of COPD and risk of venous thromboembolism. Clin Respir J 2019;13:499-504. doi:10.1111/crj.13051

34. Squizzato A, Gerdes VEA, Ageno W, et al. The coagulation system in endocrine disorders: a narrative review. Intern Emerg Med 2007;2:76-83.

35. Van Zaane B, Nur E, Squizzato A, et al. Hypercoagulable state in Cushing's syndrome: a systematic review. J Clin Endocrinol Metab 2009;94:2743-50.

36. Sneeboer MMS, Hutten BA, Majoor CJ, et al. Oral and inhaled corticosteroid use and risk of recurrent pulmonary embolism. Thromb Res 2016;140:46-50.

37. Abdelghany. Can alveolar-arterial oxygen gradient predict severity of pulmonary embolism? http:/www.ejbronchology.eg. net/article.asp?issn=1687- 8426;year=2019; volume=13;issue $=2 ;$ spage $=273$; epage $=279 ;$ aulast $=$ Abdelghany $($ accessed 6 May 2020).

38. Cohoon KP, Ashrani AA, Crusan DJ, et al. Is infection an independent risk factor for venous thromboembolism? A populationbased case-control study. Am J Med 2018;131:307-316.e2.

39. Chan TC, Vilke GM, Pollack M, et al. Electrocardiographic manifestations: pulmonary embolism. J Emerg Med 2001;21: 263-70.

40. Levis JT. ECG Diagnosis: pulmonary embolism. Perm J 2011; $15: 75$.

41. Matthews JC, McLaughlin V. Acute right ventricular failure in the setting of acute pulmonary embolism or chronic pulmonary hypertension: a detailed review of the pathophysiology, diagnosis, and management. Curr Cardiol Rev 2008;4: 49-59.

42. Günay E, Sarınç Ulaşlı S, Akar O, et al. Neutrophil-to-lymphocyte ratio in chronic obstructive pulmonary disease: a retrospective study. Inflammation 2014;37:374- 80.

43. Furutate R, Ishii T, Motegi T, et al. The neutrophil to lymphocyte ratio Is related to disease severity and exacerbation in patients with chronic obstructive pulmonary disease. Intern Med Tokyo Jpn 2016;55:223-9.

44. Paliogiannis P, Fois AG, Sotgia S, et al. Neutrophil to lymphocyte ratio and clinical outcomes in COPD: recent evidence and future perspectives. Eur Respir Rev 2018;27:170113.

45. Hogg K. CRP in the diagnosis of pulmonary embolism. Emerg Med J 2010;27:A4- A4. 
46. Agarwal R, Zaheer MS, Ahmad Z, et al. The relationship between $\mathrm{C}$-reactive protein and prognostic factors in chronic obstructive pulmonary disease. Multidiscip Respir Med 2013;8:63.
47. Gao D, Chen X, Wu H, et al. The levels of serum pro-calcitonin and high-sensitivity $\mathrm{C}$-reactive protein in the early diagnosis of chronic obstructive pulmonary disease during acute exacerbation. Exp Ther Med 2017;14:193-8. 